TABLE II-Results of verbal assessment of successful endoscopies by patients according to age under or over 45 . (Figures are numbers $(\%)$ of patients.)

\begin{tabular}{|c|c|c|c|}
\hline & $\begin{array}{c}\text { Mildly } \\
\text { unpleasant }\end{array}$ & Unpleasant & $\begin{array}{c}\text { Very } \\
\text { unpleasant }\end{array}$ \\
\hline \multicolumn{4}{|c|}{ Men } \\
\hline $\begin{array}{l}<45 \text { years } \\
>45 \text { years }\end{array}$ & $\begin{array}{l}42(64) \\
44(83)\end{array}$ & $\begin{array}{r}17(26) \\
8(15)\end{array}$ & $\begin{array}{l}7(11) \\
1(2)\end{array}$ \\
\hline $\begin{array}{l}<45 \text { years } \\
>45 \text { years }\end{array}$ & $\begin{array}{l}14(39) \\
12(38)\end{array}$ & $\begin{array}{r}m e n \\
16(44) \\
16(50)\end{array}$ & $\begin{array}{l}6(17) \\
4(13)\end{array}$ \\
\hline $\begin{array}{l}<45 \text { years } \\
>45 \text { years }\end{array}$ & $\begin{array}{l}\text { All p } \\
56(55) \\
56(66)\end{array}$ & $\begin{array}{r}\text { atients } \\
33(32) \\
24(28)\end{array}$ & $\begin{array}{c}13(13) \\
5(6)\end{array}$ \\
\hline
\end{tabular}

in whom endoscopy was successful were prepared if necessary to undergo a second endoscopy performed in the same way.

A total of 114 patients $(57 \%)$ were discharged back to the general practitioner without further follow-up.

\section{Discussion}

This study aimed at using improvements in endoscope design to provide a safe, efficient, and acceptable service to patients and general practitioners, while making optimal use of hospital facilities and resources. The results show that endoscopy performed with the P2 Olympus endoscope was successful in $93.5 \%$ of patients without premedication or intravenous sedation. No particular problems were encountered by the endoscopists, who felt that adequate examination of the upper alimentary tract was carried out in each patient and was no more difficult than routine endoscopy carried out under intravenous sedation. Analysis of the verbal and visual analogue scale assessments and the observation that 175 out of 187 patients $(94 \%)$ indicated that they would undergo a second endoscopy in the same way showed that the procedure was tolerated extremely well. Men and older patients appeared to have a higher level of tolerance.

The absence of premedication and sedation made communication with the patient after endoscopy easy. Patients could, and did, leave the hospital, return to work, or drive immediately after the procedure. As patients did not need admission to a day ward, beds, nursing staff, and other facilities were released for other use. In many cases only a single visit was necessary, saving the time spent in hospital. The average time spent in the clinic was only 45 minutes, part of which was spent on evaluative procedures, which can be omitted in the future.

Interestingly, of the 200 patients referred with specific gastrointestinal tract symptoms, 131 had endoscopic abnormality but only 21 had active duodenal or gastric ulceration while 37 had duodenal scarring. This incidence indicates the possible yield of ulcers diagnosed by endoscopy as a primary screening procedure for patients referred to hospital for investigation of dyspepsia.

\section{References}

${ }^{1}$ Doll, R, and Avery Jones, F, Occupational Factors in the Aetiology of Gastric and Duodenal Ulcers, MRC Special Report No 276. London, Medical Research Council, 1951.

${ }^{2}$ Barnes, R J, et al, British Medical fournal, 1974, 4, 214.

${ }^{3}$ Cotton, P, British Medical fournal, 1973, 2, 161.

\title{
Hospital antibiotic policy in a health district
}

\author{
R W LACEY
}

\section{Introduction}

During 1977 and 1978 a rigid antibiotic policy was adopted in the hospitals of the King's Lynn Health District (population $150000)$. A wide variety of medical and surgical patients are treated in this district, exceptions being patients needing neurosurgery, thoracic surgery, and transplants. I here describe this policy and its effect on costs and resistance.

\section{The policy}

A limited range of antibiotics was selected on the following basis. (1) When there was little evidence of differences in clinical effect between similar antibiotic analogues, then the antibiotic was selected according to cost. (2) Antibiotics that were available as both oral and parenteral preparations were favoured. (3) Few antibiotics were available for topical use (except in ophthalmology). Thus topical gentamicin was not prescribed, and the use of disinfectants (notably chlorhexidine and povidine-iodine) was encouraged. (4) A few recently introduced antibiotics were kept in reserve-for example, amikacin, cefuroxime, and cefoxitin. (5) Fixed combinations were discouraged.

Monitoring of policy-No attempt was made to direct the antibiotic prescription of every patient, but when an "unapproved" agent was prescribed or a listed agent was prescribed for an apparently inappropriate condition the prescription was questioned. In most cases such prescriptions were amended after discussion between the clinician and a pharmacist; a few were amended after discussion with the consultant microbiologist. 
General microbiological methods-Sensitivity testing was performed on all important pathogenic bacteria using the method of Stokes ${ }^{1}$; using a Multodisk, sometimes with a pre-incubated modification ${ }^{2}$; or by determining the minimum inhibitory concentration (MIC) (single cell) on Oxoid DST agar. $\beta$-Lactamase production was detected either by the chromogenic cephalosporin or a paper method (intralactam). Identification of Gram-negative bacteria was by the API method, and phage typing of Staphylococcus aureus was performed at routine test dilution with the addition of phages 94,95 , and 96 to the basic set.

Transference of resistance-Aliquots $(1.0 \mathrm{ml})$ of donor and recipient (Escherichia coli $\mathrm{K} 12 \mathrm{~J} 53$, resistant to rifampicin) were added to $10 \mathrm{ml}$ of nutrient broth and incubated overnight statically at $37^{\circ} \mathrm{C}$ then plated on medium containing $100 \mu \mathrm{g}$ of rifampicin $/ \mathrm{ml}$ with either $50 \mu \mathrm{g}$ of cephradine or $50 \mu \mathrm{g}$ cefoxitin/ml. Appropriate controls including cultures known to donate ampicillin resistance to the recipient were included.

Inactivation of antibiotics-Stationary broth cultures were filtered

TABLE I-Consumption of antibiotics (not administered topically) in grams (\%) and of chemotherapeutic agents during 1977-8

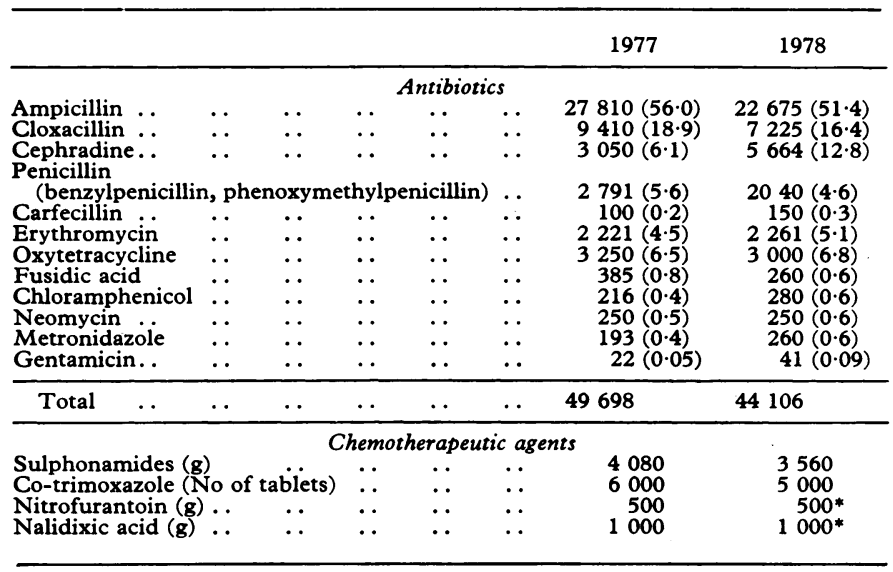

*Estimated figures. through $0.45 \mathrm{~nm}$ Millipore filters and incubated with $100 \mu \mathrm{g} / \mathrm{ml}$ antibiotic for three hours at $37^{\circ} \mathrm{C}$ and then assayed for residual activity using a plate assay method. In some experiments these antibiotics were added to whole cultures and incubated for 20 hours at $37^{\circ} \mathrm{C}$. Controls showed that little spontaneous decomposition of either antibiotic occurred.

Prevention of infection-A member of the technical staff of the microbiological laboratory (control of infection officer) monitored ward air with settle plates and performed other prophylactic procedures.

\section{Results}

Consumption of antibiotics-During the two years six antibioticsnamely, ampicillin, cloxacillin, cephradine, penicillin, erythromycin, and oxytetracycline-comprised about $98 \%$ (by weight) of al antibiotic prescriptions (table I). About $88 \%$ of all the antibiotics prescribed were $\beta$-lactam compounds. Between 1977 and 1978 the total weight prescribed was reduced by $11.3 \%$. In both years gentamicin accounted for less than $0.1 \%$ of the total. Other trends included a reduction in the use of ampicillin and cloxacillin and an increase in that of cephradine. Cephradine, the first cephalosporin available as both parenteral and oral preparations, was valuable in this policy. It was used mainly to treat wound and soft-tissue infections and urinary sepsis. The selection of $\beta$-lactamase-producing bacteria may be encouraged by using poorly absorbed $\beta$-lactam agents (for example, ampicillin), and the use of cephradine, which is well absorbed, might be associated with a lower incidence of resistance. For this reason clinicians were encouraged to prescribe cephradine rather than cloxacillin and ampicillin combinations.

Relation of resistance to use of $\beta$-lactam antibiotics-Since nearly $90^{\circ}$. (by weight) of antibiotics prescribed were $\beta$-lactam compounds, the incidence of resistance to these during the second year of the policy was assessed (table II). Ampicillin resistance occurred in $37.0 \%$ of Proteus, Klebsiella, E coli, Enterobacter, and Citrobacter, and $4.7 \%$ of these were resistant to cephradine. Eighty per cent of isolates of Staph aureus produced penicillinase, but only $1.2 \%$ were "methicillin resistant." During 1978 only three $\gamma$-lactamase-producing cultures of Haemophilus influenzae were isolated, but $83 \%$ of isolates of Bacteroides (fragilis and other species) were considered to be resistant to ampicillin.

TABLE II-Resistance of Enterobacteriaeceae (1112) to cephalosporin-type antibiotics selected initially by disc testing

\begin{tabular}{|c|c|c|c|c|c|c|}
\hline \multirow{2}{*}{ Organism } & \multirow{2}{*}{ No examined } & \multicolumn{5}{|c|}{ No resistant $(\mathrm{MIC}>20 \mu \mathrm{g} / \mathrm{ml})$ to: } \\
\hline & & Cephaloridine & Cephradine & Cefuroxime & Cefoxitin & Cefotaxime \\
\hline $\begin{array}{l}\text { Escherichia coli } \\
\text { Klebsiella aerogenes } \\
\text { Enterobacter spp } \\
\text { Proteus spp } \\
\text { Citrobacter freundii }\end{array}$ & $\begin{array}{r}15 \\
7 \\
16 \\
10 \\
22\end{array}$ & $\begin{array}{r}15 \\
7 \\
16 \\
10 \\
22\end{array}$ & $\begin{array}{r}12 \\
4 \\
12 \\
8 \\
16\end{array}$ & $\begin{array}{r}10 \\
4 \\
14 \\
6 \\
17\end{array}$ & $\begin{array}{r}2 \\
3 \\
14 \\
6 \\
14\end{array}$ & $\begin{array}{l}1 \\
1 \\
1\end{array}$ \\
\hline Total & 70 & 70 & 52 & 51 & 39 & 3 \\
\hline
\end{tabular}

MIC = Minimum inhibitory concentration.

TABLE III-Distribution of phage types* of 429 hospital strains of Staphylococcus aureus isolated during 1977-8. (Each isolate was judged to be epidemiologically distinct)
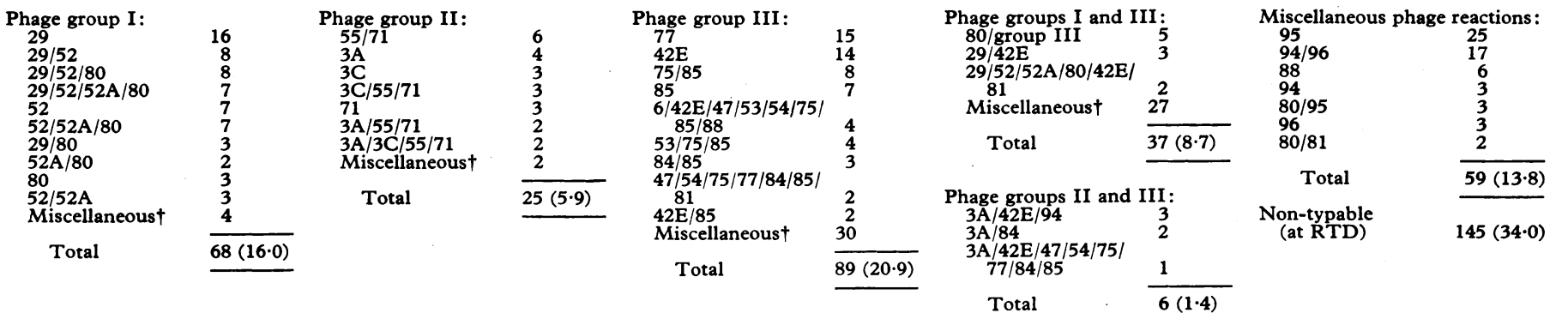

$\mathrm{RTD}=$ Routine test dilution.
*Typing at $\mathrm{RTD}$. Only major reactions ( $\geqslant 50$ plaques) recorded.

tAll cultures within these groups had different phage reactions (differing by at least one major reaction at RTD). 
Nature of cephalosporin resistance in the Enterobacteriaceae-Isolates of the Enterobacteriaceae were defined as resistant to the cephalosporins when the MIC of a single cell was greater than $20 \mu \mathrm{g}$ of the antibiotic/ml. Among the cephalosporins tested the number of resistant bacteria varied from $6.3 \%$ for cephaloridine to $0.3 \%$ for cefotaxime (table II). Resistance occurred in $E$ coli, Klebsiella, Proteus, Enterobacter, and Citrobacter. The 52 cultures resistant to cephradine and the 39 resistant to cefoxitin were examined for transferability of resistance to $E$ coli $\mathrm{K} 12$. Cefoxitin resistance was non-transferable in all; cephradine was transferable from only two cultures. The cultures
Ampicillin was used commonly for chest infections and, sometimes inappropriately, for septic cutaneous lesions. Infections due to $P$ s aeruginosa were rare and usually not treated with antibiotics. This was reflected in the low usage of gentamicin, carfecillin, and carbenicillin. Neomycin was used occasionally for bowel sterilisation. The newer cephalosporins (cefuroxime and cefoxitin) were not available when the policy was introduced, and because their position in treatment was still debatable they were not prescribed. The relatively low consumption of penicillin

TABLE IV-Cost of antibiotics $(£)$ and other therapeutic agents in King's Lynn Health District during 1974-8.

(Percentage change on previous year given in parentheses)

\begin{tabular}{llllc}
\hline & $1974-5$ & \multicolumn{1}{c}{$1975-6$} & $1976-7$ & $1977-8$ \\
\hline $\begin{array}{l}\text { Antibiotics } \\
\text { (actual cost) }\end{array}$ & 16431 & 19136 & 19476 & 19312 \\
$\begin{array}{l}\text { Antibiotics } \\
\text { (adjusted for inflation) }\end{array}$ & 16431 & $16361(-0 \cdot 4 \%)$ & $12912(-21 \cdot 1)$ & $10448(-19 \cdot 1)$ \\
$\begin{array}{c}\text { Other drugs } \\
\text { (actual cost) }\end{array}$ & 74331 & 89400 & 119851 & 156981 \\
$\begin{array}{c}\text { Other drugs } \\
\text { (adjusted for inflation) }\end{array}$ & 74331 & $76437(+2 \cdot 8)$ & $79461(+4 \cdot 0)$ & $84926(+6 \cdot 9)$ \\
\hline
\end{tabular}

resistant to cephradine and cefoxitin were examined for their ability to hydrolyse these antibiotics. Cephradine was hydrolysed by nine culture filtrates but cefoxitin was stable in the presence of all of the filtrates. When whole cultures were incubated with either cephradine or cefoxitin, however, $26(66 \%)$ of those resistant to cefoxitin decomposed the antibiotic to various extents (less than $25 \%$ of the antibiotic remained after 24 hours' incubation in the presence of the culture) and $19(36 \%)$ of the cultures hydrolysed cephradine. Subsequent experiments did not explain why whole cultures could inactivate cefoxitin while filtrates could not.

Absence of epidemic incidents-Apart from one incidence incriminating cross-infection with Staph aureus and a few instances of transfer of Pseudomonas aeruginosa between patients with indwelling catheters, there was no clear-cut evidence of cross-infection. This is shown by the enormous variety of phage types of Staph aureus isolated during the two years (table III).

Relation of policy to cost of antibiotics-During the implementation of the policy the true-that is, the inflation-adjusted-cost of the antibiotics declined (table IV). This saving was attributable to the policy in the following ways. (1) The total consumption of antibiotics dropped; (2) several of the agents were selected because they were cheaper than comparable analogues; and (3) expensive aminoglucosides - that is, gentamicin and amikacin (which was never used)were reserved for only occasional cases of sepsis.

\section{Discussion}

With this antibiotic policy six antibiotics comprised $98 \%$ of the antibiotics prescribed as oral or parenteral preparations. was partly due to the high numbers of some pathogens resistant to it (as ampicillin) and the rarity of infections due to streptococci and pneumococci.

Apart from widespread resistance to ampicillin in Staph aureus, Enterobacteriaceae, and Bacteroides, the numbers resistant to the other agents were not high. This was probably because most of the cases of sepsis were due to endogenous pathogens rather than cross-infection by hospital strains. Thus the level of resistance here probably reflects the use of antibiotics in the community rather than in hospital. Gentamicin resistance was not seen in either Enterobacteriaceae or Staph aureus isolated within the hospitals. An important purpose of the policy was to preserve the sensitivity of bacteria to gentamicin by carefully controlling its use. This was achieved partly because it was not available for topical use and partly because sensitivity to gentamicin was reported by the laboratory only when none of the other approved antibiotics would suffice.

I thank Mr D Butler, district pharmacist, for supplying the data on drug consumption, all members of the district pharmacy for their enthusiastic support, and the East Anglian Regional Health Authority for a research grant.

\section{References}

${ }^{1}$ Stokes, E J, Clinical Bacteriology, p 179. London, Edward Arnold, 1968. 2 Lacey, R W, and Stokes, A, fournal of Clinical Pathology, 1977, 30, 35.

(Accepted 27 March 1979)
ONE HUNDRED YEARS AGO Last autumn, I had an excellent opportunity of observing the effects of the seeds of laburnum on several children, who had been to the Church Sunday School, and, on their way home, plucked and ate freely of the pods of a laburnum tree in the graveyard. As they were soon attacked with evident signs of irritant poisoning, many came under my notice; and inasmuch as the symptoms varied somewhat from the results of Christison's experiments with the various parts of this plant, and also from those mentioned in one or two text-books to which $I$ have referred, I have thought a short epitome of the principal symptoms would be of interest. My little patients varied in age from six to fourteen years. I could not ascertain what quantity of the seeds had been ingested, but presume that, from the very nauseous and disagreeable taste, this could not have been large.

The symptoms commenced, in from ten to fifteen minutes, with violent abdominal pain, followed in most cases by nausea and vomiting, which persisted in some for two or three hours. Then followed somewhat rapidly great depression, amounting in the more severe cases to violent prostration. There were in no case the tetanic convulsions mentioned by Christison, nor did I hear of any purgation. The pupil was markedly dilated. The pulse was very rapid and feeble, and the face became red and suffused, perspiration appearing about the forehead. The exhaustion continued for some hours, being followed by drowsiness. I did not notice any other head-symptom. The treatment I adopted consisted chiefly in administering emetics, where the plant itself did not seem to act satisfactorily in this respect, and in one or two cases I gave a little ammonia and bark, ordering the friends to watch the children carefully. The symptoms had in most cases disappeared the following morning. One or two complained of general weakness and languor for a few days. There was no fatality.

(British Medical fournal, 1879.) 